Jurnal Farmamedika Vol. 1, No. 1 Juni 2016

\title{
POTENSI EKSTRAK AIR DAUN ALPUKAT(Persea americana M.) SEBAGAI DIURETIKPADA TIKUS PUTIH JANTAN
}

\author{
Triyani Sumiati ${ }^{1 *}$., Ferry Effendi ${ }^{1}$.,Muhamad Sofyan Iskandar ${ }^{1}$ \\ 1. Program Studi Farmasi Sekolah Tinggi Teknologi Industri dan Farmasi Bogor \\ *Korespondensi: triyanisumiati@gmail.com
}

\begin{abstract}
ABSTRAK
Diuretika adalah suatu senyawa yang dapat merangsang pengeluaran urin.Kandungan senyawa flavonoid yang terkandung dalam ekstrak daun alpukat memiliki aktivitas diuretik.Penelitian ini bertujuan untuk mengetahui senyawa flavonoid yang terkandung dalam ekstrak airdaun alpukat yang memiliki aktivitas diuretik. Pengujian dilakukan dengan pemberian ekstrak air daun alpukat secara per oral terhadap 30 ekor tikus putih jantan galur Sprague-Dawley dengan berat badan 200 gram yang dibagi dalam 6 kelompok. Konsentrasi ekstrak air daun alpukat yang diberikan 5\%, $10 \%$, 15\% dan 20\% serta Furosemid tablet sebagai kontrol postif.Frekuensi urinasi dengan pemberian ekstrak air daun alpukat 5\%,10\%,15\% dan 20\% secara berturut-turut yaitu 2, 5, 9 dan 20 kali dengan pengamatan selama 3 jam.Frekuensi urinasi tablet Furosemid adalah 25 kali selama 3 jam. Hasil penelitian menunjukkan bahwa ekstrak air daun alpukat 20\% memiliki aktivitas diuretik setara dengan tablet Furosemid dengan dosis 7,2 mg/200 mg BB pada tikus putih jantan.
\end{abstract}

\section{Kata kunci : daun alpukat, diuretik, ekstrak air, flavonoid, furosemid.}

\begin{abstract}
Diuretics is a substance that can stimulate of urine output. The content of flavonoid compunds contained in water extracts of avocado leaves have a diuretic activity. Testing is done withgiving a water extract of avocado leaves per oral to 30 male rats strain (Sparague-Dawley) with weight 200 grams were divided into 6 groups. Frequency of urination with water extract of avocado leaves $5 \%$ $, 10 \%, 15 \%$ and $20 \%$ respectively which is $2,5,9$ and 20 times with observation for 3 hours. Furosemide tablets urination frequency was 25 times over 3 hours. The result showed that the water extract of avocado leaves $20 \%$ have diuretic activity is equivalent to Furosemide tablets at a dose of $7.2 \mathrm{mg} / 200 \mathrm{mg}$ BB in male rats.
\end{abstract}

Keywords : avocado leaves, diuretic, flavonoid, furosemid, water extract

\section{PENDAHULUAN}

Diuretika adalah suatu senyawa yang dapat merangsang pengeluaran urin.Senyawa ini dapat mempengaruhi secara langsung transpor zat terlarut dalam air melalui ginjal.Senyawa yang dapat merangsang pengeluaran urin sangat potensial untuk digunakan dalam keadaan seperti gagal jantung, nefrosis, hipertensi dan lain-lain [1].

Kecenderungan masyarakat dunia untuk kembali ke alam membawa perubahan dari pola konsumsi obat terhadap obat-obatan yang terbuat dari bahan alami.Berdasarkan data WHO tahun 2007, sekitar $80 \%$ penduduk dunia untuk perawatan kesehatannya memanfaatkan obat tradisional yang berasal dari ekstrak tanaman [2]. Masyarakat Indonesia sudah sejak ratusan tahun yang lalu memiliki tradisi memanfaatkan tanaman dari lingkungan sekitarnya sebagai obat tradisional yang dikenal dengan nama jamu. Fenomena ini terus meningkat sejak krisis ekonomi tahun 1997 yang menyebabkan harga obat sintetik melonjak tinggi karena sebagian besar bahan baku obat sintetik tersebut merupakan komoditi impor. Tingginya minat masyarakat Indonesia akan obat yang berasal dari tanaman (obat herbal) mengakibatkan banyak perusahaan industri farmasi nasional yang menawarkan produk obat herbal dalam bentuk ekstrak tanaman obat yang diolah dan dikemas secara modern di pasaran [3]. 
Daun alpukat (Persea americanaM.) secara historis telah dijadikan sebagai obat herbal yang dimanfaatkan sebagai pelancar pengeluaran air seni, penghancur batu di saluran kemih, dan sebagai obat sariawan. Bagian yang digunakan untuk ramuan tradisional adalah daun karena mengandung gula, $\delta$-parseit, flavonoid quersetein, dan senyawa sterin [4].Penyebab batu ginjal beraneka ragam, salah satunya adalah karena masuknya zat nefrotoksik ke dalam tubuh, yang di antaranya adalah senyawa etilen glikol.

Penelitian ini ingin membuktikan manfaat daun alpukat yang merupakan salah satu obat herbal yang diduga bersifat sebagai diuretik.Hasil penelitian Wientarsih et al. [5] menunjukkan bahwa ekstrak etanol daun alpukat mengandung flavonoid pada dosis 100 $\mathrm{mg} / \mathrm{kg}$ BB dan $300 \mathrm{mg} / \mathrm{kb}$ BB yang bekerja sebagai diuretik dan antioksidan.Ekstrak etanol daun alpukat berperan sebagai diuretik karena memberikan pengaruh terhadap peningkatan pengeluaran urin, dengan dosis optimum 100 $\mathrm{mg} / \mathrm{kg}$ BB[6]. Pemberian infusum daun alpukat dapat menaikan laju filtrasi glomerulus, menghambat kenaikan ureum dan kreatinin. Selain itu juga dapat menghambat kristalisasi urin pada ginjal tikus[7]. Berdasarkan uraian di atas, penelitian ini bertujuan untuk menentukan potensi ekstrak air daun alpukat pada tikus putih jantan sebagai diuretik dan dibandingkan dengan sediaan tablet Furosemid sebagai kontrol positif.

\section{METODE PENELITIAN}

Bahan: Serbuk simplisia daun alpukat yang diperoleh dari BALITRO,furosemid tablet, akuades, $\mathrm{NH}_{3}$, Kloroform, $\mathrm{H}_{2} \mathrm{SO}_{4}$, pereaksi meyer, pereaksi dragendorf, $\mathrm{Mg}, \mathrm{HCl}$, etanol, amil alkohol, $\mathrm{FeCl}_{3}$ dan asetat anhidrat.

Hewan Uji : Hewan uji yang akan digunakan adalah tikus putih jantan (Rattus novergicus) galur Sprague-Dawley dengan berat badan 200 gram sejumlah 30 ekor.

Alat: Kandang khusus untuk pengamatan uji diuretik, bejana, corong, timbangan analitik, timbangan hewan, batang pengaduk, kertas saring, stop watch, termometer, masker, sarung tangan, beaker glass, gelas ukur, erlenmeyer, alat ukur $\mathrm{pH}$, sonde lambung, tabung reaksi dan plat tetes, evaporator, nampan, alat bedah dan kawat.

\section{Metode \\ Preparasi Sampel}

Sampel yang digunakan adalah simplisia daun alpukat (Persea americana M.) yang telah berbentuk serbuk dengan pengayakan ukuran 40 mesh. Sampel diperoleh dari Balai Penelitian Tanaman Rempah dan Obat (BALITRO), Jl. Tentara Pelajar No. 3, Kampus Penelitian Pertanian Cimanggu, Kota. Bogor 16111, Jawa Barat.

\section{Penentuan Kadar Air}

Penentuan kadar air berguna untuk mengetahui batasan maksimal atau kisaran kandungan air dalam bahan. Hal ini berhubungan dengan daya simpan simplisia, sehingga jika melebihi batas yang ditentukan akan sangat mempengaruhi waktu kadaluarsa dari simplisia tersebut. Pengerjaannya dilakukan dengan cara cawan porselin dikeringkan pada suhu $105^{\circ} \mathrm{C}$ selama 3 jam, kemudian didinginkan dalam eksikator selama 30 menit dan ditimbang untuk mengetahui bobot kosong dari cawan. Sebanyak 3 gram sampel dimasukkan ke dalam cawan porselin dan dimasukkan ke dalam oven pada suhu $105^{\circ} \mathrm{C}$ selama 6 jam, kemudian didinginkan dan ditimbang kembali [8]. Rumus perhitungan kadar air, sebagai berikut:

$$
\text { Kadar air }(\%)=\frac{a-b}{a} \times 100 \%
$$

$\mathrm{a}=$ bobot sampel sebelum pemanasan $(\mathrm{g})$

$\mathrm{b}=$ bobot sampel setelah pemanasan $(\mathrm{g})$

\section{Pembuatan Ekstrak Air Daun Alpukat}

Pembuatan ekstrak daun alpukat dilakukan dengan cara ekstraksi seduhan. Ditimbang 100 gram serbuk daun alpukat dan dimasukan kedalam gelas kimia, kemudian ditambahkan air panas dengan suhu $70^{\circ} \mathrm{C}$ sebanyak $1000 \mathrm{ml}$ selama 10 menit, sambil diaduk.Seduhan serbuk daun alpukat didiamkan hingga dingin dan di saring dengan menggunakan kertas saring ke dalam labu erlenmeyer. Setelah itu filtrat diuapkan dengan evaporator selama 2 jam dengan suhu $70^{\circ} \mathrm{C}$ dan kecepatan $70 \mathrm{rpm}$ untuk mendapatkan ekstrak kental.Ekstrak kental yang diperoleh kemudian dihitung $\%$ rendemennya dengan rumus:

Rendemen $(\%)=\frac{\text { bobot ekstrak kental }(g)}{\text { bobot serbuk }(g)} \times 100 \%$
Selanjutnya esktrak kental yan diperoleh kemudian diencerkan menjadi 4 macam konsentrasi untuk empat perlakuan, yaitu $5 \% \mathrm{~b} / \mathrm{v}, 10 \% \mathrm{~b} / \mathrm{v}, 15 \% \mathrm{~b} / \mathrm{v}$ dan $20 \% \mathrm{~b} / \mathrm{v}$.

\section{Uji Fitokimia[9]}

a. Uji Alkaloid

Sebanyak $500 \mathrm{mg}$ sampel ditambahkan $1 \mathrm{ml}$ asam klorida $2 \mathrm{~N}$ dan $10 \mathrm{ml}$ air, panaskan di 
penangas air selama 2 menit, dinginkan dan saring.Kemudian dibagi menjadi 2 tabung reaksi.Pada tabung pertama dimasukkan pereaksi Mayer, hasil dinyatakan (+) jika terbentuk endapan putih.Pada tabung kedua dimasukkan perekasi Dragendorff, hasil dinyatakan (+) bila terbentuk endapan merah jingga.

b. Uji Flavonoid

Tiga metode digunakan untuk menguji flavonoid.Pertama ditetesi $\mathrm{FeCl} 31 \%$ pada $500 \mathrm{mg}$ sampel.Warna hijau kehitaman yang dihasilkan menunjukkan adanya kandungan flavonoid.Kedua, beberapa tetes larutan timbal asetat $10 \%$ ditambahkan pada sampel, terbentuknya endapan kuning menunjukkan adanya flavonoid. Ketiga, sampel dilarutkan dalam etanol ditambahkan serbuk magnesium, $1 \mathrm{ml} \mathrm{HCl}$ pekat ditambahkan dari sisi tabung reaksi, warna magenta menunjukkan adanya flavonoid.

c. Uji Saponin

Sebanyak $500 \mathrm{mg}$ sampel ditambahkan $5 \mathrm{ml}$ akuades dalam tabung reaksi.Dikocok kuatkuat, adanya saponin ditandai dengan terbentuk busa yang stabil.

d. Uji Tanin

Sebanyak $500 \mathrm{mg}$ sampel direbus dengan 10 $\mathrm{ml}$ akuades dalam tabung reaksi selama 5 menit, kemudian disaring.Filtrat ditetesi $\mathrm{FeCl}_{3} 1 \% . \mathrm{Uji}$ positif ditandai dengan munculnya warna hijau kecoklatan atau biru kehitaman.

e. Uji Steroid dan Triterpenoid

Sebanyak 25 mg ekstrak dilarutkan dalam 2 $\mathrm{ml}$ kloroform dalam tabung reaksi, disaring dan filtrat, lalu ditambahkan 10 tetesasetat anhidrat kemudian dikocok dengan baikdan $1 \mathrm{ml}$ asam sulfat pekat ditambahkan dengan hati-hati pada dinding tabung reaksi. Reaksi (+) steroid berwarna coklat kemerahan, reaksi $(+)$ triterpenoid bila terbentuk cincin berwarna merah.

\section{Persiapan Hewan Uji}

Hewan uji yang digunakan dalam penelitian ini adalah tikus putih jantan, dengan bobot 200 gram sebanyak 30 ekor yang dibagi dalam 6 kelompok dengan masing-masing kelompok berjumlah 5 ekor tikus putih jantan, yaitu PI, PII, PIII dan PIV diberi larutan ekstrak air daun alpukat berturut-turut dengan konsentrasi yaitu 5\%, 10\%, 15\% dan 20\%.PV diberi kontrol positif (+) dengan tablet furosemid dosis 7,2 mg/200 BB tikus dan PVI diberi kontrol negatif (-) dengan akuades.

\section{Penetapan Dosis Furosemid Tablet}

Dosis furosemid tablet untuk manusia sebesar $40 \mathrm{mg} /$ hari dikonversi kepada dosis tikus dengan juga menyertakan faktor konversi dari manusia ke tikus sebesar 0,018 dan faktor farmakokinetika sebesar 10. Jadi, penetapan dosis furosemid tablet $=40 \mathrm{mg} \times 0,018 \times 10=$ 7,2 mg. Dengan demikian, digunakan dosis furosemid tablet sebesar 7,2 $\mathrm{mg} / 200 \mathrm{BB}$ tikus.Untuk 1 perlakuan terdiri dari 5 pengulangan tikus $=7,2 \mathrm{mg}$ x $5=36 \mathrm{mg}[10]$.

\section{Metode Pengujian Aktivitas Diuretik Pada Hewan Uji \\ Uji aktivitas diuretik pada hewan uji,} terlebih dahulu hewan uji yaitu tikus putih jantan dipuasakan selama \pm 18 jam. Tikus putih jantan yang digunakan sebanyak 30 ekor yang dibagi menjadi 6 kelompok, tiap kelompok terdiri dari 5 ekor. Pada kelompok pertama diberikan akuades secara per oral sebagai kontrol negatif. Kelompok kedua diberikan tablet furosemi dengan dosis 7,2 mg/200 BB tikus secara per oral sebagai kontrol positif. Kemudian kelompok ketiga, keempat, kelima dan keenam diberikan ekstrak air daun alpukat berturut-turut dengan konsentrasi 5\%, 10\%, $15 \%$ dan $20 \%$ secara per oral. Volume pemberianobat untuk hewan uji disesuaikan pada tabel konversi dan tabel volume pemberian agar tidak melebihi jumlah tertentu. Volume pemberian yang diberikan yaitu 5 $\mathrm{ml} / 200$ gram BB per oral.Pada pengamatan yang dilakukan, tikus jantan putihmasingmasing ditempatkan dalam kandang khusus yang tersedia, kemudian diamati frekuensi mengeluarkan urin, pencatatanwaktu keluarnya urin, warna urin dan volume urin yang dikeluarkan. Pengamatan dilakukan selama 3 jam setiap perlakuan. 
Tabel 1. Pengujian masing-masing perlakuan hewan uji

\begin{tabular}{|c|c|c|c|c|c|c|}
\hline \multirow{2}{*}{ Perlakuan } & \multicolumn{7}{|c|}{ Kelompok Hewan Uji } \\
\cline { 2 - 7 } & I & II & III & IV & V & VI \\
& K (-) & K (+) & $\mathbf{( 5 \% )}$ & $\mathbf{( 1 0 \% )}$ & $\mathbf{( 1 5 \% )}$ & $\mathbf{( 2 0 \% )}$ \\
\hline Furosemid Tablet & - & $\sqrt{10}$ & - & - & - & - \\
Ekstrak Air Daun Alpukat & - & - & $\sqrt{ }$ & $\sqrt{ }$ & $\sqrt{ }$ & $\sqrt{ }$ \\
Akuades & $\sqrt{ }$ & - & - & - & - & - \\
\hline
\end{tabular}

Keterangan:(-) Tidak diberikan perlakuan

$(\sqrt{ })$ Diberikan perlakuan

\section{Analisa Data}

Data yang diperoleh kemudian dihitung persentase frekuensi urinasi dari setiap kelompok. Kemudian dilakukan perbandingan aktivitas dari setiap kelompok dosis ekstrak terhadap kelompok pembanding oleh furosemid tablet.Selanjutnya dilakukan analisa data secara statistik menggunakan Analisis of Varian (ANOVA) secara regresi linear untuk memperoleh hasil data pada tingkat kepercayaan $95 \%$.

\section{HASIL DAN PEMBAHASAN Pembuatan Simplisia}

Sampel yang digunakan pada penelitian ini adalah simplisia daun alpukat (Persea Americana M.).Simplisia daun alpukat dibuat serbuk dengan ukuran saringan 40 mesh.Simplisia yang telah diserbukkan memiliki warna hijau muda dan berbau khas daun alpukat. Simplisia yang digunakan pada penelitian ini adalah serbuk daun alpukat kemudian ditentukan kadar airnya. Penetapan kadar air berguna untuk menyatakan kandungan zat dalam tumbuhan sebagai persen bahan kering. Pengeringan sampel bertujuan agar sampel terhindar dari kerusakan atau berkurangnya kualitas sampel disebabkan oleh mikroba ataupun jamur sehingga sampel dapat disimpan dalam jangka waktu yang lama. Hasil kadar air yang telah dilakukan dalam penelitian ini sebesar $5,40 \%$.Kadar air yang baik adalah kurang dari $10 \%$ [11]

\section{Penyiapan Ekstrak Air Daun Alpukat}

Penyiapan ekstrak air daun alpukat dilakukan dengan menggunakan metode ekstraksi secara seduhan dengan pelarut air.Penggunaan ekstraksi secara seduhan karena pelarut yang digunakan adalah air, dimana air merupakan pelarut yang bersifat polar yang dapat menarik senyawa-senyawa aktif seperti saponin, flavonoid dan tanin.Faktor penting dalam pemilihan pelarut adalah sifat pelarutnya, kemampuan untuk mengekstrak, tidak bersifat racun, kemudahan untuk diuapkan [12]. Air dipilih sebagai cairan penyari karena keterkaitannya dengan senyawa yang diduga memiliki kemampuan dalam memberikan aktivitas diuretik yaitu flavonoid. Dalam proses ekstraksi secara seduhan suhu yang digunakan adalah $70{ }^{0} \mathrm{C}$ yang bertujuan agar senyawasenyawa aktif yang terdapat didalam tanaman tidak rusak selama proses ekstraksi khususnya flavonoid. Hasil proses ekstraksi 100 gram serbuk simplisia menghasilkan filtrat yang kemudian diuapkan dengan menggunakan evaporator sehingga didapatkan ekstrak kental sebanyak 11,61 gram berwarna coklat kehitaman. Perhitungan rendemen rata-rata ekstrak sebesar 11,61\%, dilakukan untuk menilai efektivitas metode ekstraksi yang digunakan.

\section{Uji Fitokimia}

Setelah proses ekstraksi selesai dilakukan penapisan fitokimia yang bertujuan untuk mengetahui kandungan senyawa aktif yang terdapat didalam ekstrak. Penapisan dilakukan terhadap golongan senyawa alkaloid, flavonoid, saponin, tanin, steroid dan triterpenoid.Dari hasil uji alkaloid dengan menggunakan pereaksi Mayer dan Dragendroff menunjukkan hasil negatif, ini dikarenakan oleh sifat alkaloid yang non polar sehingga tidak larut dalam air atau sedikit larut dalam air.Uji flavonoid yang dilakukan memberikan hasil yang positif dimana adanya perubahan warna hijau kehitaman dengan penambahan $\mathrm{FeCl}_{3}$.Flavonoid merupakan senyawa polihidroksi (gugus hidroksil) maka flavonoid bersifat polar sehingga dapat larut dalam air dan senyawa polar lainnya.Uji tanin menunjukkan hasil positif dengan terbentuknya warna hijau kecoklatan, ini dikarenakan tanin merupakan senyawa polifenol yang bersifat larut dalam air.Uji saponin menunjukkan hasil positif yang ditandai dengan pembentukan busa atau buih yang stabil dalam waktu 10 menit.Uji steroid dan triterpenoid memberikan hasil negatif karena senyawa steroid dan triterpenoid merupakan senyawa yang mengandung gugus hidrokarbon yang bersifat non polar sehingga tidak larut dalam air. 
Tabel 2.Hasil uji fitokimia

\begin{tabular}{|l|c|l|}
\hline \multicolumn{1}{|c|}{ Zat Aktif } & Hasil & \multicolumn{1}{c|}{ Keterangan } \\
\hline Alkaloid & - & $\begin{array}{l}\text { 1. Mayer : Tidak terbentuk endapan putih } \\
\text { 2. Dragendroff : Tidak terbentuk endapan merah jingga }\end{array}$ \\
\hline Flavonoid & + & Warna hijau kehitaman \\
\hline Tanin & + & Warna hijau kecoklatan \\
\hline Saponin & + & Terbentuk busa \\
\hline Steroid & - & Tidak ada perubahan warna coklat kemerahan \\
\hline Triterpenoid & - & Tidak terbentuk cincin warna merah \\
\hline
\end{tabular}

Keterangan : (+) : Positif, mengandung zat aktif

(-) : Negatif, tidak mengandung zat aktif

\section{Hasil Uji Diuretik Pada Hewan Uji Frekuensi Keluarnya Urin}

Pada penelitian ini dilakukan uji aktivitas ekstrak air daun alpukat sebagai diuretik pada tikus putih jantan.Jenis tikus putih jantan yang digunakan adalah Sprague-Dawley dengan berat badan 200 gram sebanyak 30 ekor. Tikus putih jantan ini dibagi menjadi 6 kelompok perlakuan, yaituperlakuan I (PI)ekstrak daun alpukat 5\%, perlakuan II (PII) ekstrak daun alpukat $10 \%$, perlakuan III (PIII) ekstrak daun alpukat $15 \%$, perlakuan IV (PIV) ekstrak daun alpukat $20 \%$, perlakuan V (PV) furosemid tablet dan perlakuan VI (PVI) akuades dimana setiap kelompok terdiri dari 5 ekor hewan uji. Sampel uji yang digunakan adalah ekstrak air daun alpukat dalam bentuk ekstrak kental yang digunakan sebagai diuretik.Ekstrak kental daun alpukatdibagi dalam 4 konsentrasi yaitu 5\%,10\%, 15\% dan $20 \%$.Sedangkan kontrol positif yang digunakan adalah furosemid tablet yang umumnya digunakan sebagai diuretik dan kontrol negatifnya menggunakan akuades. Volume pemberian obat dan ekstrak air daun alpukat terhadap hewan ujimasing-masing sebanyak 5 $\mathrm{ml} / 200$ gram BB melalui per oral serta pengamatan dilakukan selama 3 jam.

Tabel 3. Frekuensi keluarnya urin pada tiap hewan uji selama 3 jam

\begin{tabular}{|c|c|c|c|c|c|c|}
\hline \multirow[t]{2}{*}{ Perlakuan } & \multicolumn{5}{|c|}{$\begin{array}{l}\text { Frekuensi Keluarnya Urin Tiap Hewan } \\
\text { Uji }\end{array}$} & \multirow[t]{2}{*}{$\begin{array}{c}\text { Jumlah Frekuensi } \\
\text { Keluarnya Urin }\end{array}$} \\
\hline & 1 & 2 & 3 & 4 & 5 & \\
\hline Ekstrak 5\% & 1 & 0 & 1 & 0 & 0 & 2 \\
\hline Ekstrak 10\% & 0 & 1 & 1 & 1 & 2 & 5 \\
\hline Ekstrak 15\% & 2 & 2 & 2 & 1 & 2 & 9 \\
\hline Ekstrak 20\% & 4 & 5 & 4 & 3 & 4 & 20 \\
\hline Furosemid Tablet & 4 & 5 & 4 & 6 & 6 & 25 \\
\hline Akuades & 0 & 1 & 0 & 1 & 0 & 2 \\
\hline
\end{tabular}

Hasil pada Tabel 3 menunjukkan frekuensi keluarnya urin pada PI dengan pemberian ekstrak air daun alpukat $5 \%$ menghasilkan frekuensi urinasi sebanyak 2 kali dari 5 ekor hewan uji selama 3 jam. Pada PII dengan pemberian ekstrak air daun alpukat $10 \%$ menghasilkan frekuensi urinasi sebanyak 5 kali dari 5 ekor hewan uji selama 3 jam. Pada PIII dengan pemberian ekstrak air daun alpukat $15 \%$ menghasilkan frekuensi urinasi sebanyak 9 . kali dari 5 ekor hewan uji selama 3 jam. Pada PIV dengan pemberian ekstrak air daun alpukat $20 \%$ menghasilkan frekuensi urinasi sebanyak 20 kali dari 5 ekor hewan uji selama 3 jam.Pada PV dengan pemberian furosemid tablet menghasilkan frekuensi urinasi sebanyak 25 kali dari 5 ekor hewan uji selama 3 jam. Pada PVI dengan pemberian akuades menghasilkan frekuensi urinasi sebanyak 2 kali dari 5 ekor hewan uji selama 3 jam. 


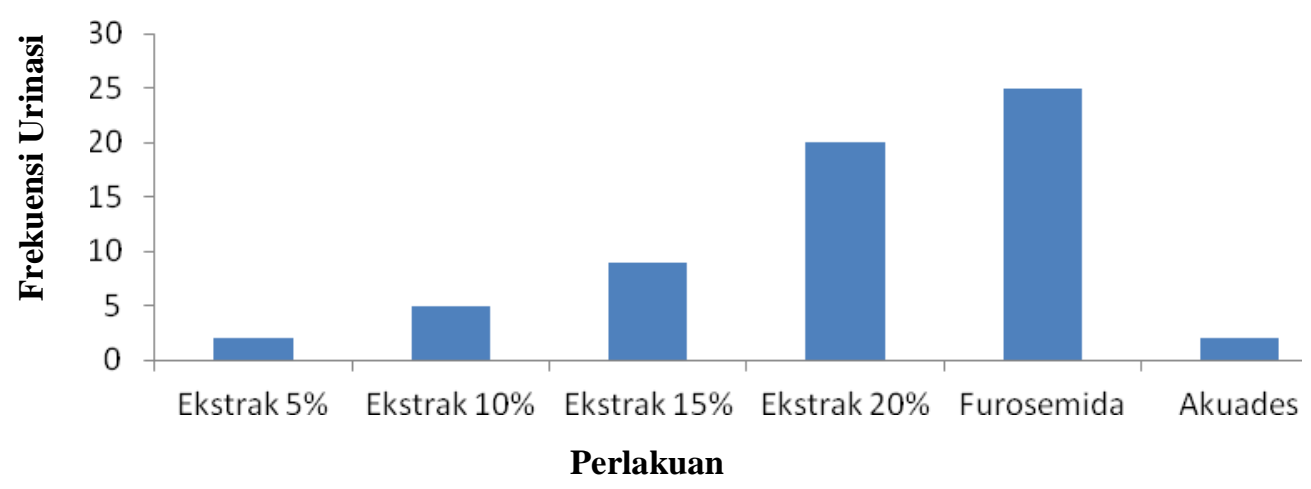

\section{Gambar 1.Frekuensi urinasi pada tiap kelompok perlakuan hewan uji}

Pada Gambar 1 diatas dapat dilihat perbedaan frekuensi urinasi antar tiap kelompok perlakuan. Frekuensi urinasi tertinggi yaitu pada kelompok perlakuan yang diberikan furosemid tablet, yaitu sebanyak 25 kali dan dengan pemberian ekstrak air daun alpukat $20 \%$ sebanyak 20 kali, sedangkan frekuensi urinasi terendah yaitu pada pemberian ekstrak air daun alpukat $5 \%$ dan akuades.

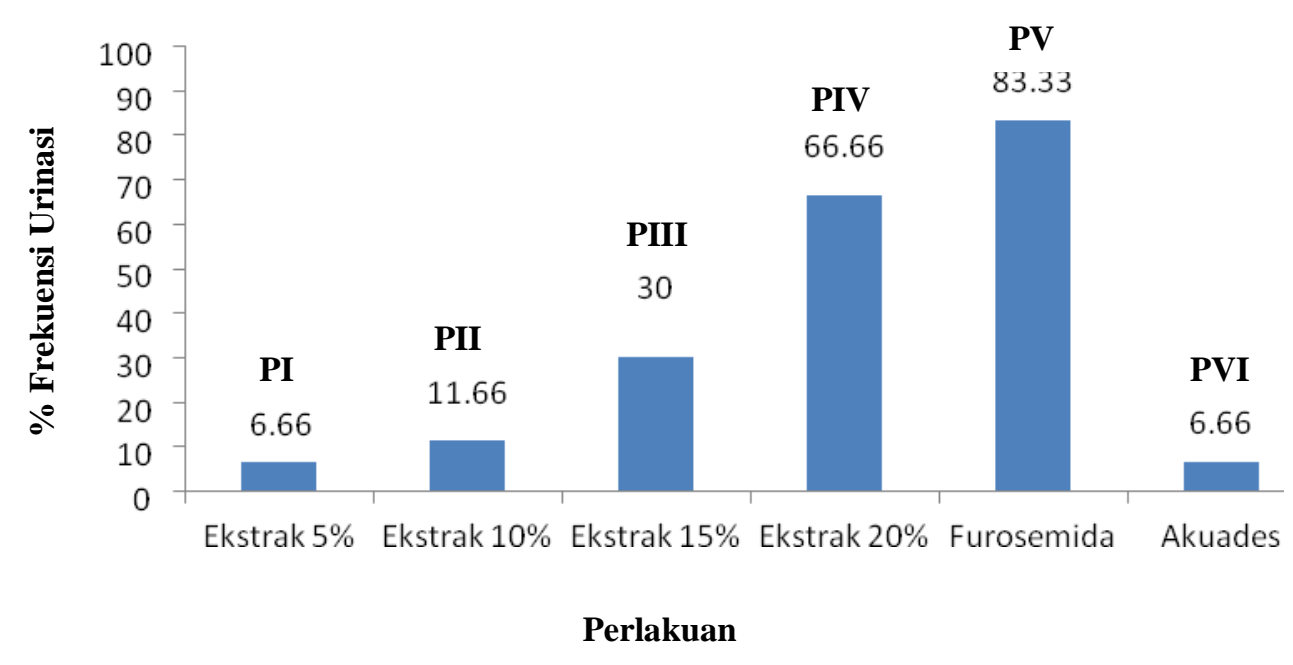

\section{Gambar 2. Persentase frekuensi urinasi pada tiap kelompok perlakuan hewan uji}

Persentase frekuensi keluarnya urin pada tiap kelompok perlakuan hewan uji dapat dilihat pada Gambar 8. Persentase frekuensi urinasi tertinggi yaitu pada kelompok perlakuan dengan pemberian furosemid tablet yaitu $83,33 \%$ dan kelompok perlakuan dengan pemberian ekstrak 20\% yaitu $66,66 \%$. Persentase terendah yaitu pada pemberian ekstrak 5\%,10\%, 15\% dan akuades secara berturut-turut sebesar 6,66\%, 11,66\%, 30\% dan $6,66 \%$. Dilihat dari persentase tertinggi menunjukkan bahwa ekstrak $20 \%$ memiliki aktivitas diuretik yang mendekati dengan tablet furosemid dosis $7,2 \mathrm{mg} / 200 \mathrm{~g}$ BB tikus. Adanya aktivitas diuretik pada pemberian ekstrak $20 \%$ menunjukkan bahwa ekstrak air daun alpukat memiliki potensi sebagai diuretik. Aktivitas diuretik dalam ekstrak air daun alpukat dikarenakan adanya senyawa flavonoid. Hal ini sesuai dengan penelitian sebelumnya yang telah dilakukan oleh Wientarsih et al. (2014) menyatakan bahwa ekstrak etanol daun alpukat mengandung flavonoid bekerja sebagai diuretik dan antioksidan.Ekstrak etanol daun alpukat juga berperan sebagai diuretik karena memberikan pengaruh terhadap peningkatan urinasi (Adha, 2009).

\section{Waktu Keluarnya Urin}

Pengamatan waktu keluarnya urin dilakukan setelah diinduksi melalui per oral terhadap setiap hewan uji.Pengamatan pengeluaran urin dilakukan selama 3jam. Waktu keluarnya urinyang dicatat 
25 | Triyani Sumiati, et.al.( Potensi Ekstrak Air ...)

yaitu pada jam saat pertama kali hewan uji mengeluarkan urin pertama. Waktu yang didapatkan pada saat pengeluaran urin yang

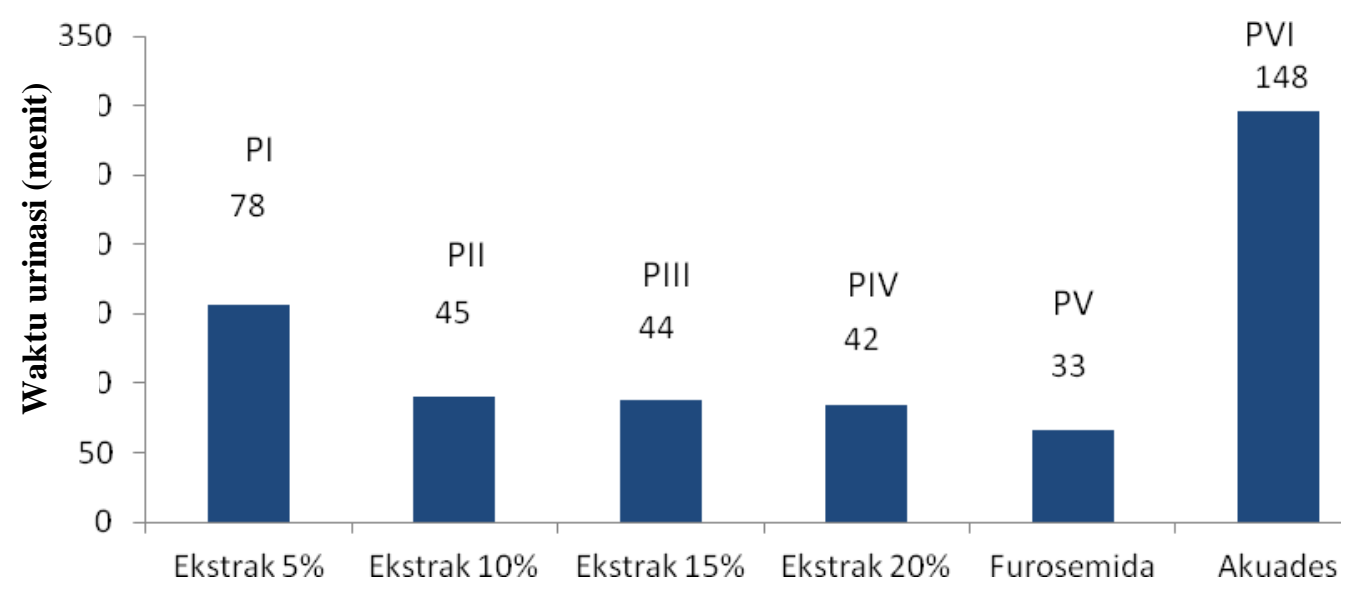

pertama dikurangi waktu pada saat dinduksi, sehingga dapat diketahui waktu efek diuretik yang diberikan oleh masing-masing sampel uji.

\section{Perlakuan}

\section{Gambar 3.Waktu urinasi pada tiap kelompok perlakuan hewan uji}

Hasil menunjukkan bahwa waktu efek diuretik dengan pemberian furosemid tablet terjadi pada menit ke-33 setelah pemberian secara per oral. Dengan pemberian ekstrak $20 \%$ waktu efek diuretik terjadi pada menit ke-42, dibandingkan dengan pemberian ekstrak $5 \%$, $10 \%, 15 \%$ dan akuades secara berturut-turut terjadi pada menit ke-78, 45, 44 dan 148. Dengan demikian, waktu efek diuretik yang mendekati furosemid tablet sebagai kontrol positif adalah dengan pemberian ekstrak $20 \%$.

\section{Volume dan Warna Urin}

Pengamatan volume dan warna urin terhadap hewan uji menunjukkan bahwa dengan pemberian ekstrak air daun alpukat 5\% dan akuades secara kualitatif volume pengeluaran urin sangat sedikit serta memiliki warna jernih untuk ekstrak air daun alpukat dan jernih kekuningan dengan pemberian akuades. Dengan pemberian ekstrak air daun alpukat $10 \%, 15 \%, 20 \%$ dan tablet furosemid dosis 7,2 $\mathrm{mg} / 200 \mathrm{~g}$ BB tikus memiliki volume pengeluaran urin yang banyak serta memiliki warna jernih.

Tabel 4.Volume dan warna urin pada hewan uji

\begin{tabular}{|ccc|}
\hline Perlakuan & Volume Urin & Warna Urin \\
\hline Ekstrak 5\% & $0,8 \mathrm{ml}$ & Jernih \\
Ekstrak 10\% & $2 \mathrm{ml}$ & Jernih \\
Ekstrak 15\% & $2,3 \mathrm{ml}$ & Jernih \\
Ekstrak 20\% & $2,7 \mathrm{ml}$ & Jernih \\
Furosemid Tablet & $3 \mathrm{ml}$ & Jernih \\
Akuades & $0,5 \mathrm{ml}$ & Jernih kekuningan \\
\hline
\end{tabular}


26 | Triyani Sumiati, et.al.( Potensi Ekstrak Air ...)

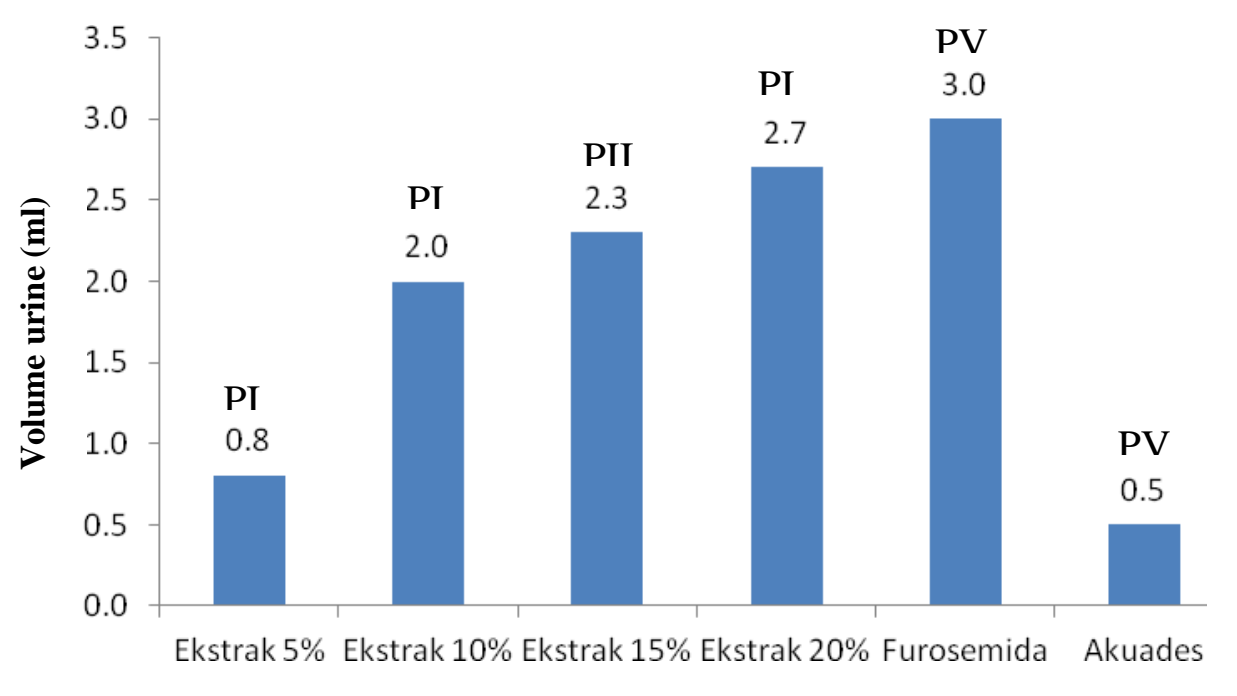

Perlakuan

\section{Gambar 4. Volume urin dan warna pada tiap kelompok perlakuan hewan uji}

Berdasarkan hasil yang diperoleh volume urin dan warna urin tiap perlakuan hewan uji masing-masing berbeda. Pada PI, PII, PII, PIV dan PV secara berturut-turutdidapat volume urin sebanyak $0,8 \mathrm{ml}, 2,0 \mathrm{ml}, 2,3 \mathrm{ml} 2,7$ $\mathrm{ml}$ dan 3,0 $\mathrm{ml}$ serta memiliki warna urin yang jernih. Sedangkan untuk PVI didapat volume urin sebanyak $0,5 \mathrm{ml}$ dan memiliki warna jernih kekuningan

\section{SIMPULAN}

Berdasarkan hasil penelitiaan yang telah dilaksanakan dapat disimpulkan bahwa ekstrak air daun alpukat mengandung flavonoid, saponin dan tanin.Hasil uji invivo ekstrak air daun alpukat $5 \%, 10 \%, 15 \%$ dan $20 \%$ dapat memberikan aktivitas diuretik pada tikus putih jantan. Ekstrak air daun alpukat 20\% memiliki aktivitas diuretik sebesar $66,66 \%$ sedangkan tablet furosemid $83,33 \%$..

\section{SARAN}

Perlu dilakukan penelitian lebih lanjut untuk mendapatkan dosis optimal ekstrak air daun alpukat yang bermanfaat sebagai diuretik.

\section{DAFTAR PUSTAKA}

[1] Syamsudin dan Darmono. 2011. Farmakologi Eksperimental. Jakarta: Buku Ajar. Penerbit UI. Hal: 8, 21.

[2] Zaenal, 2008. Optimalisasi Produksi Obat Tradisional pada Taman SYIFA [Skripsi] Bogor: Institut Pertanian Bogor.

[3] Dorly. 2005. Potensi Tumbuhan Obat Indonesia Dalam Pengembangan IndustriAgromedisin [Tesis] Bogor: Institut Pertanian Bogor.
[4] Maryani. 2003. Tanaman Obat untuk Mengatasi Penyakit pada Usia Lanjut. Jakarta: PT Agromedia Pustaka.

[5] Wientarsih I. 2014. Aktivitas Ekstrak Etanol Daun Alpukat (Persea americana M.) Terhadap Batu Ginjal Buatan dan Diuretik padaTikus Putih [Skripsi]. Bogor : Institut Pertanian Bogor.

[6] Adha, 2009. Pengaruh Pemberian EkstrakEtanol Daun Alpukat (Persea americana M.) Terhadap Aktivitas Diuretik Tikus Putih Jantan Sprague Dawley. [Skripsi] Bogor: Insitut Pertanian Bogor.

[7] Madystuti R. 2010. Pengaruh Infusum Daun Alpukat (Persea americana M.) dalam Menghambat Kristal Urin yang Diinduksikan Etilen Glikol Pada Tikus Putih Jantan. [Tesis]. Bogor: Program Pasca Sarjana, Institut Pertanian Bogor.

[8] (AOAC) Assosiation of Officiale Analytical Chemist. 1995. Official Methods of Analysis of AOAC International. Washington DC: AOAC International.

[9] Rajendraet al, 2011 Metode Fitokimia Penuntun Cara Modern Menganalisis Tumbuhan. Terbitan pertama. Surabaya: UNAIR.

[10] Gunawan,W. 2014. Efek Pemberian Ekstrak Etanol 70\% Tanaman Suruhan (Piperomia pellucida(L). H.B.K) Terhadap 
27 | Triyani Sumiati, et.al.( Potensi Ekstrak Air ...)

Kadar Asam Urat Darah Tikus Putih Jantan Yang Diinduksi Kalium Oksalat. [skripsi]. Bogor: STTIF Bogor.

[11] Winarno, F.G. 1997. Kimia Pangan dan Gizi. Jakarta: Gramedia

[12]Harborne, 1996. Metode Fitokimia Penuntun Cara Modern Menganalisis Tumbuhan. Terbitan kedua. Terjemahan K.

Padmawinata dan 1. Soediro. Bandung: ITB. 